\title{
AGORA, SIM!!! LANÇAMENTO DA CAMPANHA NURSING NOW BRASIL.
}

Pronunciamento oficial - Isabel Amélia Costa Mendes

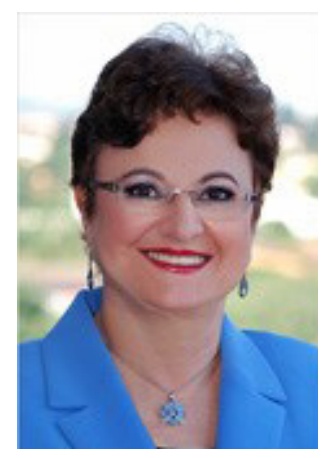

Nursing Now é um programa desenvolvido pela Burdett Trust for Nursing em nome da Organização Mundial de Saúde (OMS) e do Conselho Internacional de Enfermeiras. International Council of Nurses - ICN.

Representa, a partir da valorização da Enfermagem e obstetrizes, possibilidades para o desenvolvimento global, cujos sistemas de saúde estejam fortalecidos e empenhados na excelência do atendimento às demandas de saúde dos diferentes povos para os quais a enfermagem exerce os seus cuidados, com vistas a promoção e recuperação da saúde, prevenção de doenças e, consequentemente, manutenção da vida com qualidade que cada ser humano e suas familias merecem.

Nesse contexto, a Campanha Nursing Now está sustentada em fortes evidências que conclamam a atenção de lideranças e organismos internacionais e locais, compromissados com a saúde dos povos para o desenvolvimento da humanidade, a valorizarem a enfermagem como contexto de transformação social, na perspectiva da saúde ; pois, há que se considerar que toda pessoa, de forma direta ou indireta, em algum período do ciclo da vida, será cuidada pela enfermagem. Adicionalmente, é inquestionável o contributo que estes estes profissionais entregam para a efetiva consolidação das políticas públicas de saúde.

Apesar da notoriedade desse entendimento, destacam-se as evidências, compreensões e marco histórico que impulsionam a importância da Campanha Nursing Now, a saber:

- O bicentenário de nascimento de Florence Nightingale, no ano de 2020. Para a ocasião, cabe destacar que a influência desta enfermeira não reflete êxitos apenas da Enfermagem, mas para toda a humanidade a partir de seu notório legado para os sistemas de saúde e de cuidados;

- Oapontamento da Assembléia Mundial da Saúde de que a meta de alcance de 1 bilhão de pessoas beneficiadas pela Cobertura Universal de Saúde não será alcançada sem o devido investimento na enfermagem, de modo que esses profissionais possam desenvolver seu trabalho na completa extensão de suas habilidades, conhecimentos e potencialidades;

- $\quad$ argumento de que todos os países que investirem e desenvolverem sua força de trabalho de enfermagem podem expandir rapidamente, e com rentabilidade o alcance da cobertura universal de saúde de alta qualidade ${ }^{(1-2)}$ e ainda, nas seguintes assertivas do relatório:

- Ofocono financiamento eacesso em cobertura universal de saúde encontra-se em avançada superação; agora é preciso direcionar fortemente o foco em qualidade dos serviços, promoção de saúde e prevenção de doençasem cujas esferas os enfermeiros podem desempenhar um papel crescente;

- Os enfermeiros estão bem posicionados: para atender as necessidades de saúde em mudança, especialmente doenças não-transmissiveis; para oferecer níveis crescentes de promoção de saúde e prevenção de doenças; para desenvolver cuidados primários e oferecer apoio e supervisão aos agentes comunitários de saúde. Contudo, muitas vezes esses profissionais não recebem o merecido apoio para exercerem, com plenitude, o seu verdadeiro potencial de transformação a partir de seu trabalho. Isto significa um extraordinário desperdício de talento e de recursos, cujos impactos afetam diretamente a população. Existem enfermeiros que já avançaram em seus papéis especializados e muitos serviços por eles liderados globalmente oferecem inovadores e exitosos modelos de cuidado. Isto pode ser o ponto de partida para uma expansão rápida e econômica de cobertura universal, e qualificada de saúde ${ }^{(1-2)}$.

A Organização Mundial da Saúde encoraja, por isso, todos os países a abraçarem a política de investimento na enfermagem como forma de promover o cuidado centrado nas pessoas e de criar oportunidades de emprego qualificado para mulheres e jovens, assim alcançando a cobertura universal de saúde ${ }^{(2: 4)}$.

Desse modo, corrobora-se o entendimento do Dr. Tedros Ghebreyesus, Diretor Geral da OMS, ao mencionar que: "os governos devem entender o emprego de enfermeiros não como custo, mas como investimento em desenvolvimento sustentável.... Adiante, acrescenta: “Enfermeiras não são apenas essenciais para a oferta de serviços de saúde; sua experiência e conhecimento representam um valioso capital na formulação das políticas de saúde e sua voz merece ser ouvida na mesa de definição politica"(2:4).

A campanha baseia-se nos dados desses relatórios substantivos, o relatório do triplo impacto(1) e o relatório WISHWorld Innovation Summit for Health(2), que advoga que o fortalecimento do papel da enfermagem é vital e estratégico no contexto das equipes multidisciplinares de saúde. Este relatório traz a conclusão de que o investimento nos profissionais de enfermagem promove a melhoria da saúde globalmente, contribui também para o alcance da igualdade de gênero, já que a grande maioria dos enfermeiros ainda é constituída por mulheres, e consequentemente contribui também para se construir economias mais fortes. Assim, tal investimento integra e consubstancia três objetivos integrantes do conjunto de Objetivos de Desenvolvimento Sustentável da ONU: saúde $^{(3)}$, Igualdade de gênero(5) e Emprego Digno e Crescimento Econômico(8) 
- Objetivo 3-Assegurar uma vida saudável e promover o bem-estar para todos, em todas as idades;

- Objetivo 5: Alcançar a igualdade de gênero e empoderar todas as mulheres e meninas:

- Objetivo 8: Promover o crescimento econômico sustentado, inclusivo e sustentável, emprego pleno e produtivo e trabalho decente para todos

Assim, a campanha representa um forte incentivo para empoderar os enfermeiros a assumirem o papel central no enfrentamento dos desafios de saúde do século XXI, usando todo o potencial de sua competência profissional e de sua liderança. Até o final de 2020, objetiva aumentar a influência dos enfermeiros e intensificar suas contribuições para garantir que todos tenham acesso à saúde e aos cuidados em saúde.

Enfim, existe consenso de que a meta de acesso e cobertura universal de saúde Não será alcançada SEM a contribuição efetiva da Enfermagem ${ }^{(1-9)}$.

Várias manifestações sobre essa questão refletem o conceito vibrante e dinâmico da Campanha Nursing Now, como também o reconhecimento e interesse contínuo dos governos de mais de 60 países que já aderiram `a Campanha.

Entendo que uma celebração global estava sendo gestada há vários anos com a proximidade do marco histórico da Enfermagem; mas o movimento Nursing Now ultrapassou os limites inicialmente planejados: nasceu, em termos, para marcar o bicentenário de nascimento de Florence Nightingale, mas, sobretudo, tem o seu nascedouro em áreas externas 'a enfermagem e que enxergam seu valor e significado social e econômico.

A parceria entre o Centro Colaborador da OPAS/OMS para o desenvolvimento da Pesquisa em Enfermagem, localizado na Escola de Enfermagem de Ribeirão Preto da Universidade de São Paulo (EERP/USP) e o Conselho Federal de Enfermagem - COFEn foi oficializada em 14 de outubro de 2018, pela Portaria COFEn 1495. Esta portaria estabeleceu um Grupo de Trabalho sob nossa coordenação representando o Centro Colaborador. Embora oficializada em outubro de 2018, desenvolvemos durante 5 meses um processo de trabalho prévio para obtenção das credenciais da Campanha Global, e assim podermos instituir a liderança da Campanha Nursing Now Brasil. Essas tratativas demandaram longo e detalhado processo que se tornou oficialmente aprovado em setembro de 2018.

Com esta aprovação fornecida chancelada pela Diretora Executiva da Campanha Nursing Now Global, passamos a responder como a Contact Person da Campanha Nursing Now Brasil. Deste modo, unidos em parceria, o COFEn e o Centro Colaborador da OPAS/OMS para o Desenvolvimento da Pesquisa em Enfermagem- EERP/USP detêm o direito de usar a logomarca (marca registrada) da Campanha, desenvolver ações e cumpre o dever de promover o Lançamento Nacional na capital de nosso país e ativar o desenvolvimento de ações, mobilizando lideranças locais em todo o território nacional.

Nosso compromisso é estimular os enfermeiros de todo este maravilhoso país a darem o melhor de si; vamos nos dedicar a dar visibilidade ao diferencial que podemos marcar na assistência 'a saúde brasileira. Toda inciativa será valiosa e muito bem recebida.

Mas, comecemos porumpontovital, sem oqualos esforçosnão serão recebidos como devidamente merecidos: A VALORIZAÇÃO da ENFERMAGEM. E isto começa, necessariamente, por nós mesmos: a postura de auto -valorização é o item crucial da agenda da enfermagem brasileira. Encaremos, com vontade e positividade, uma primeira fase de chamamento interno de autovalorização e auto- confiança, independente das circunstâncias de trabalho que estejamos vivenciando hoje. Façamos da adversidade uma oportunidade de mudança, de força, de vigor, de desenvolvimento e de inovação.

Passemos, então, para uma segunda fase de demonstração de presença e visibilidade documental de nossas ações nos serviços onde atuamos; não deixemos de registrar tudo o que fazemos; temos que mostrar, provar, tornar visível, documentar, assumir autoria e responsabilidade por inovações que introduzimos com frequência nos serviços. Esse movimento criará uma repercussão positiva na própria equipe de enfermagem, nas equipes de saúde, de tal modo que os gestores tornem -se sensiveis ao fato de que os enfermeiros são capazes de fazer diferença, que podem adicionar e agregar mais valor no cenário da saúde, e de que conjuntamente com as equipes interprofissionais, contribuem significativamente para a condução de uma trajetória de crescimento sustentável do sistema de saúde.

Enquanto isso acontece, gradativamente, a terceira fase vai se delineando e se instalando com a projeção de valor e de visibilidade profissional na sociedade, com reconhecimento e respeito.

'A medida em que demonstramos nossas ações na internalidade das equipes e dos serviços, estamos também canalizando em todo o ambiente profissional esses valores para a clientela e para a sociedade.

Transversalmente, as instituições estarão investindo também, ao máximo de suas potencialidades, na formação e no desenvolvimento contínuo de seus talentos, na certeza de que vivemos numa era de aprendizagem ao longo da vida- o que pressupõe compromissos institucionais com investimento nas pessoas trabalhadoras.

Brasilia - DF, Brasil, 24 de abril de 2019 


\section{REFERÊNCIAS}

1-All-Party Parliamentary Group on Global Health: Triple Impact - how developing nursing will improve health, promote gender equality and support economic growth; London, 17 October 2016. Available from: http://www.appg.globalhealth.org.uk/

2-Crisp N. Brownie S, Refsum C. Nursing and Midwifery. The key to the rapid and cost-effective expansion of high-quality universal health coverage. Doha, Qatar: World Innovation Summit for Health. 2018. Available from: https://www.wish.org qa/wp-content/uploads/2018/11/IMPJ6078-WISH-2018-Nursing-181026.pdf

3- Denham Dm, Crisp N. Brownie S. Foreword. Nursing and Midwifery. The key to the rapid and cost-effective expansion of high-quality universal health coverage. Doha, Qatar: World Innovation Summit for Health, 2018.p.05. Available from: https://www.wish.org.qa/wp-content/uploads/2018/11/IMPJ6078-WISH-2018-Nursing-181026.pdf

4- Crisp N. Iro E. Nursing Now Campaign:raising the status of nurses.The Lancet Vol 391 March 10.920-921 2018 .[Internet]. 2018. Available from: https://www.the-

lancet.com/pb-assets/Lancet/pdfs/S014067361830494X.pdf
5-Institute of Medicine Committee on the Robert Wood Johnson Foundation Initiative on the Future of Nursing. The future of nursing. Leading change, advancing tiative on the Future of Nursing. The future of nursing: Leading change, advancing
health. Washington, DC: National Academies Press; 2011. Available from: https:// www.ncbi.nlm.nih.gov/pubmed/24983041

6-ICN. Nurses: A Force for Change - Care Effective, Cost Effective. International Council of Nurses, 2015. Available from: https://www.twna.org.tw/frontend/un07 international/webPages_3/file/Link1\%20IND_2015_Eng.pdf

7-WHO. Strategic directions for nursing and midwifery development 2016-2020: The way forward. Available from: http://www.who.int/hrh/news/2015/13_11_2015 SDNM_consultation_draft_zero.pdf

8-Crisp N: One world Health - an overview of global health. CRC Press, June 2016 pl8-19. Available from: https://www.crcpress.com/One-World-Health-An-Overview-of-Global-Health/Crisp/p/book/9781498739412

9-Ghebreyesus,T.A.- All roads lead to universal health coverage. The Lancet Global Health 5(9) June 2017. Available from: https://doi.org/10.1016/S2214$109 \times(17) 30295-4$ 